\title{
Antibodies to intermediate filaments in polymyalgia rheumatica and giant cell arteritis: a sequential study
}

\author{
B DASGUPTA, ${ }^{1}$ O DUKE, ${ }^{1}$ V KYLE, ${ }^{2}$ D G MACFARLANE, ${ }^{1}$ \\ B L HAZLEMAN, AND G S PANAYI
}

From the 'Rheumatology Unit, UMDS, Guy's Hospital, London; and ${ }^{2}$ Addenbrooke's Hospital, Cambridge

SUMMARY Serum specimens from 35 patients with polymyalgia rheumatica and giant cell arteritis (PMR/GCA) were obtained sequentially at variable time intervals up to a year from onset of disease. These were tested for antibodies to intermediate filaments by indirect immunofluor- $\vec{\oplus}$ escence using $\mathrm{HEp}_{2}$ cells as substrate. Twenty four of $35(68 \%)$ patients' sera at onset of disease $\vec{\circ}$ were positive at an anti-intermediate filament antibody (AIFA) titre of $>1 / 40$ compared with three out of $19(15 \%)$ control sera. AIFA were predominantly of IgM class, and there was no $\stackrel{+}{\circ}$ significant change in AIFA titres on follow up despite clinical remission of disease.

Key words: cytoskeleton, connective tissue disease, immunofluorescence.

The cytoskeleton of the eukaryotic cell is composed of three groups of fibrillar structures: microtubules (24 $\mathrm{nm}$ diameter), microfilaments $(6 \mathrm{~nm})$, and intermediate filaments $(10 \mathrm{~nm})$. The intermediate filaments are themselves classified into five groups according to their histological origin: ${ }^{2}$ desmin (muscle), cytokeratins (epithelial origin), vimentin (mesenchymal origin), glial (glial tissue), and neurofilaments (neuronal origin).

Antibodies to intermediate filaments have been found in the sera from patients with certain viral infections such as infectious mononucleosis and hepatitis $A, B$, and non- $A$, non- $B^{3-5}$ and with various rheumatic diseases, including rheumatoid arthritis, systemic lupus erythematosus; and polymyositis, ${ }^{6-8}$ by using either immunofluorescence or solid phase radioimmunoassay techniques. The presence of these antibodies is thought to indicate an unregulated autoimmune state. Polymyalgia rheumatica and giant cell arteritis (PMR/ GCA) are diseases of unknown aetiology characterised clinically by pain and stiffness in hip and shoulder girdle muscles or inflammation in cranial arteries accompanied by a marked acute phase response. In addition, certain immunological abnormalities, including the presence of antimitochondrial antibodies, have been described by some ${ }^{9}$ but not all investigators. ${ }^{10}$ There have been no studies,

Accepted for publication 30 April 1987.

Correspondence to Professor G S Panayi, Rheumatology Unit, UMDS, Guy's Hospital, London SE1 9RT. however, on the prevalence of antibodies to intermediate filaments in PMR/GCA.

In the present study we show that sera fremv patients with PMR/GCA commonly contain ani bodies directed against the cytoskeletal comp $\overline{\text { er- }}$ nents, vimentin and prekeratin.

\section{Materials and methods}

S E R A

Serum samples from 35 patients with PMR/GCA were obtained over a six to 12 month follow up. Of these, 15 patients (all PMR) were seen at Guy's Hospital and 20 (14 PMR, 6 GCA) at Adden brooke's Hospital. Samples were taken at onseto before steroid therapy and at variable times after wards. Serum samples from 19 age and sex matchecB controls attending the rheumatology clinic at Guy's Hospital for non-inflammatory conditions were alsQ tested. All sera were stored at $-20^{\circ} \mathrm{C}$.

DETECTION OF ANTI-INTERMEDIATE

FILAMENT ANTIBODIES (A IFA)

The human laryngeal carcinoma cell line $\mathrm{HEp}_{2}$ was used as substrate. ${ }^{11}$ Cells from stock cultures werఱ్ట్ trypsinised and grown as monolayers on multispot slides for $24-72$ hours at $37^{\circ} \mathrm{C}$ in RMPI 1640 medium (Gibco, Paisley, Scotland) supplemented with $10 \%$ fetal calf serum, $300 \mathrm{mg} / \mathrm{l}$ glutamine, and $100 \mathrm{U} / \mathrm{m} \%$ penicillin and streptomycin in a humidified $5 \% \mathrm{CO}_{20}$ incubator. Twelve hours before their use in tests 0.5 $\mathrm{mg} / \mathrm{l}$ of colchicine was added to the cultures. The ce落 
Table 1 Number and percentage of patients with PMR/GCA and controls with IgM antibodies in the sera to intermediate filaments at a titre $>1 / 40$

\begin{tabular}{lclll}
\hline \multirow{2}{*}{ Nroup } & No positive $(\%)$ & \multicolumn{2}{l}{ Reactivity } & against: \\
\cline { 3 - 5 } & & Vimentin & Prekeratin & Vimentin+prekeratin \\
\hline PMR/GCA $(\mathrm{n}=35)$ & $24(68)^{*}$ & 7 & 4 & 11 \\
Control $(\mathrm{n}=19)$ & $3(15)$ & 2 & 1 & 0 \\
\hline
\end{tabular}

*Two sera contained IgG antibodies directed against vimentin.

Percentage of IgM AIFA of the total positive was $22 / 24(92 \%)$.

monolayers were fixed in absolute methanol at $-20^{\circ} \mathrm{C}$ for 10 minutes and washed with phosphate buffered saline (PBS) at $\mathrm{pH} 7 \cdot 2$. Sera were initially screened by applying a 1:10 dilution for 45 minutes at $37^{\circ} \mathrm{C}$. The slides were then washed with PBS and fluorescein isothiocyanate (FITC) conjugated sheep antihuman immunoglobulin was applied at a 1:40 dilution. In subsequent experiments FITC conjugated sheep antihuman $\mu, \gamma$, and $\alpha$ chain antisera (Wellcome Diagnostics, Dartford, England) were used to determine the immunoglobulin class of antibodies in positive sera. Serum samples giving a positive result at 1:10 dilution were subsequently diluted further gradually to obtain the maximal dilution of serum which would give a positive result.

STAINING PATTERN OF AIFA

Serum samples positive for AIFA of vimentin specificity stain cytoplasmic filamentous bundles which are collapsed around the nucleus in colchicine treated $\mathrm{HEp}_{2}$ cells. Sera positive for AIFA of prekeratin specificity stain uncollapsed filaments that extend to the cell periphery.

IMMUNOGLOBULIN MEASUREMENT

Serum immunoglobulins were measured by kinetic

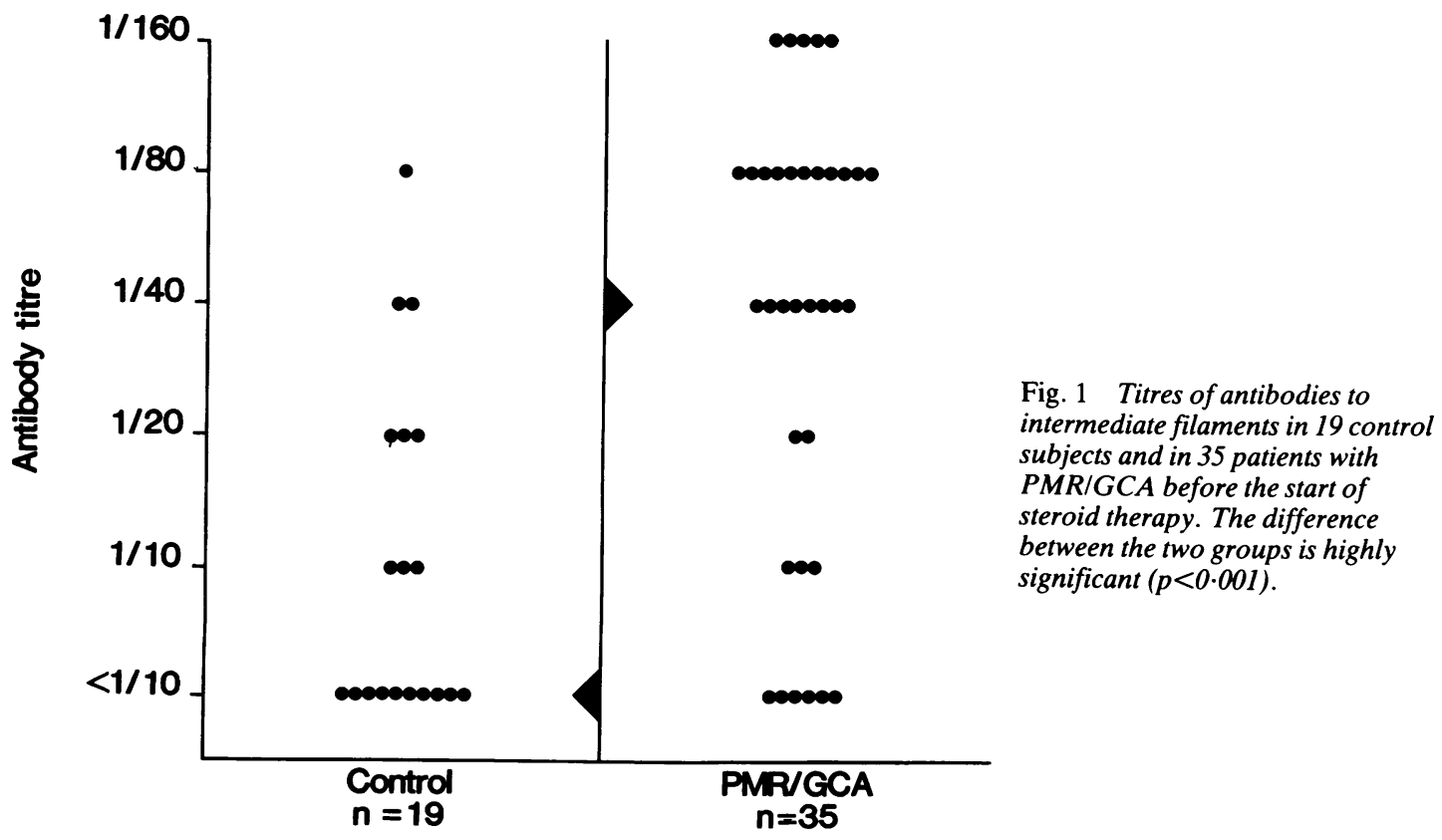
intermediate filaments in 19 control subjects and in 35 patients with . The difference between the two groups is highly significant $(p<0.001)$. 
immunoturbidimetry using a centrifugal analyser ${ }^{12}$ and expressed as grams per litre.

\section{IMMUNOFLUORESCENT MICROSCOPY}

Cultured cells stained for AIFA were examined on an epifluorescence microscope with a $200 \mathrm{~W}$ mercury lamp as source of illumination.

STATISTICAL ANALYS IS

Statistical analysis of the differences in AIFA titre between control and patient groups was by $\chi^{2}$ test.

\section{Results}

PREVALENCE OF AIFA IN PMR/GCA

(Table 1/Fig. 1)

The prevalence and titres of AIFA in PMR/GCA sera were found to be much greater than in age and sex matched controls. At a titre of $1 / 40$ and above 24 out of $35(68 \%)$ of PMR/GCA (20/29 PMR and 4/6 GCA) were positive compared with three out of 19 $(15 \%)$ of controls. The geometric mean AIFA titre in PMR/GCA was $1 / 40$ compared with $<1 / 10$ in the controls. A $\chi^{2}$ analysis of the two groups was significant at $\mathrm{p}<0.001$ (Fig. 1).

ISOTYPE DISTRIBUTION OF AIFA IN PMR (Table 1)

The AIFA in PMR sera were predominantly $(92 \%)$ of the IgM class. Of these, 18 showed reactivity against vimentin and 15 against prekeratin. Eleven sera showed specificity for both vimentin and

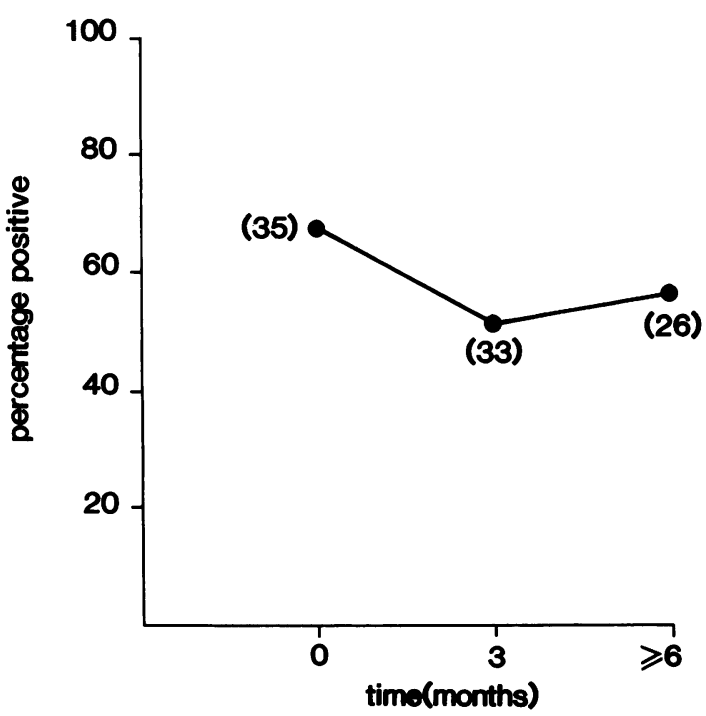

Fig. 2 Percentage of PMR/GCA sera with AIFA titre $>1 / 40$ at various times after the onset of disease. Figures within brackets show the number of patients at each time interval. None of the differences are statistically significant. prekeratin at identical titres. Two out of $35(6 \%)^{\frac{1}{3}}$ also showed IgG AIFA, with one of these sera음. showing exclusively antivimentin reactivity and the : other reactivity against both vimentin and prekera- $\overrightarrow{\overrightarrow{\vec{\omega}}}$ tin. All the positive control sera showed only IgMo AIFA. IgA AIFA were not found in either group.

SEQUENTIAL STUDIES (Fig. 2)

In 26 patients studied up to one year after onset no significant change in the percentage of positive sera ${ }^{\infty}$ or geometric mean titre was observed, though at the $\vec{\odot}$ end of six months all but one were in clinical $\vec{\longrightarrow}$ remission, with normal erythrocyte sedimentation $\omega_{\sigma}^{\omega}$ rates (ESR) and $C$ reactive protein levels in 32 outo of 35 patients.

SERUM IMMUNOGLOBULIN LEVELS

Serum immunoglobulin levels in all 35 patients sera $\vec{\circ}$ were within normal limits (data not shown), except $+\vec{\sigma}$ one patient with PMR whose serum IgM level waso $3.9 \mathrm{~g} / \mathrm{l}$ (upper limit of normal) and who had $\operatorname{IgM}_{-}^{\supset}$ AIFA at a titre of $1 / 40$.

\section{Discussion}

These findings demonstrate for the first time a highro

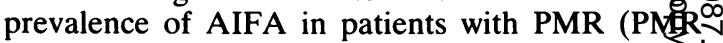
$68 \% v$ controls $15 \%)$. These antibodies are p\%dominantly of the IgM class and may be present inaa titre as high as $1 / 160$. These findings are in concordance with studies of AIFA in viral infections ando other connective tissue diseases, where the AIFA음 tend to belong solely to the IgM class. ${ }^{4-8}$ Fur $-\frac{0}{7}$ thermore, over at least a six month follow up period? in 26 patients there was no significant change in antibody titre and no evidence of change in isotype distribution in the AIFA response.

The high prevalence of AIFA raises the question of their origin and role in the pathogenesis of disease. AIFA occur predominantly in diseaseș. which are either caused by viral infection or medio ated by immune mechanisms. The high prevalence of IgM AIFA in infectious mononucleosis and malaria ${ }^{3}{ }^{13}$ has prompted the theory that AIFA max arise because of polyclonal $B$ cell stimulatio giving rise to antibody secretion by autoreactive cell clones. It is unlikely that this is the underlying mechanism in PMR as serum immunoglobulins are only occasionally and minimally raised ${ }^{14} 15$ and apart from conflicting reports of antimitochondrialy antibodies, ${ }^{9} 10$ there is no evidence of any other autoantibody response. Only one of our patients had an increased serum IgM level, and this patien. had an AIFA titre of only $1 / 40$.

The other modes of induction of AIFA could include cross reactivity between viral proteins an $\Phi^{\circ}$ 
human intermediate filament (IF) proteins, ${ }^{16} 17$ or the interaction of virus with IF could make the latter immunogenic. In this respect, it is interesting to note that the acquisition of a viral component into a host protein, histidyl-tRNA synthetase, can render the latter autoimmunogenic. ${ }^{18}$ Thus, analogously, the interaction between IF and a viral protein or, alternatively, the presence of a cross reacting epitope on these two proteins may lead to the production of an AIFA response. The relatively low titres of AIFA found in the present study and the lack of evidence of isotype switching in the immune response, however, suggest that either an immature $\mathrm{B}$ cell is involved in AIFA production or that this is not a classical antigen driven antibody response. With regard to the latter, it has recently been shown that such AIFA are present in germ free mice, and that on exposure to environmentally derived antigens such antibodies may lose their specificity and affinity for IF and acquire by somatic mutation specificity for the inducing antigen. ${ }^{19}$ This finding, together with the observation in this study and others of AIFA in some normal subjects, suggests that the genetic information for AIFA is contained within the germ line and such AIFA producing cells may exist as part of the internally activated $B$ cell repertoire.

The range of internally activated $B$ cells appears to be subject to intense regulatory control via a network of idiotype-anti-idiotype interactions. ${ }^{20}$ Thus a breakdown in these control mechanisms, such as may be expected on exposure to environmental agents, may explain the presence of low titre IgM AIFA and is supported by the finding of such antibodies after viral infections. Similarly, the presence of AIFA in PMR may reflect a disturbance of the normal immunoregulatory network operating in this disease as a consequence of environmentally acquired infection. Indirect evidence for such immunoregulatory abnormalities in PMR has been obtained with the recent demonstration of very low levels of circulating CD8 positive suppressor/ cytotoxic $\mathrm{T}$ cells by ourselves and others. ${ }^{2}{ }^{22}$

In conclusion, therefore, the finding of low titre IgM AIFA in the serum of PMR may be taken as further evidence in support of the autoimmune nature of the disorder and may reflect the interaction of an environmentally derived stimulus with the host immune system as is suggested by epidemiological and family studies.

Dr Bhaskar Dasgupta is a recipient of an Arthritis Research Council Fellowship, and we would like to thank the ARC for supporting this work. We would also like to thank Mrs Pattie Powell for typing the manuscript.

\section{References}

1 Lazarides E. Intermediate filaments as mechanical integrators of cellular space. Nature 1980; 283: $249-56$.
2 Osborn M, Geisler N, Shaw G, Sharp G, Weber K. Intermediate filaments. Cold Spring Harbor Symp Quant Biol 1981; 46: 413-29.

3 Linder E, Kurki P, Anderson L C. Antoantibody to intermediate filaments in infectious mononucleosis. Clin Immunol Immunopathol 1979; 14: 411-7.

4 Toh B H, Yildiz A, Sotelo J, et al. Viral infections and IgM autoantibodies to cytoplasmic intermediate filaments. Clin Exp Immunol 1979; 27: 76-81.

5 Brown C, Pederson J, Underwood J R, et al. Autoantibodies to intermediate filaments in acute viral hepatitis $A, B$ and non 'Anon B are directed against vimentin. J Clin Lab Immunol 1986; 19: $1-4$.

6 Kataaha P K, Mortazavi-Milani S M, Russell G, Holborow E J. Anti-intermediate filament antibodies, antikeratin antibody, and antiperinuclear factor in rheumatoid arthritis and infectious mononucleosis. Ann Rheum Dis 1985; 44: 446-9.

7 Kurki P, Helve T, Virtanen I. Antibodies to cytoplasmic intermediate filaments in rheumatic diseases. J Rheumatol 1983; 10: $558-62$.

8 Senecal J L, Oliver J M, Rothfield N. Anticytoskeletal autoantibodies in the connective tissue diseases. Arthritis Rheum 1985; 8: 889-98.

9 Sattar M A, Cawley M I D, Hamblin T J, Robertson J C. Polymyalgia rheumatica and antimitochondrial antibodies. Ann Rheum Dis 1984; 43: 264-6.

10 Mouritsen S, Demant E, Permin H, Wick A. High prevalence of antimitochondrial antibodies among patients with some well defined connective tissue diseases. Clin Exp Immunol 1986; 66: 68-76.

11 Kataaha P K. Studies of lymphoćyte responsiveness and autoantibody production in human malaria. University of London, 1985: 96-8. (PhD thesis.)

12 Spencer K, Price C P. Kinetic immunoturbidimetry: the estimation of albumin. Clin Chim Acta 1979; 95: 263-76.

13 Mortazavi-Milani S M, Badakere S S, Holborow E J. Antibody to intermediate filaments of the cytoskeleton in the sera of patients with acute malaria. Clin Exp Immunol 1984; 55: 177-82.

14 Malmnvale B E, Bengtsson B A, Kayser B, Nilsson L A, Alestig K. Serum levels of immunoglobulins and complement in giant cell arteritis. JAMA 1976; 236: 1876-8.

15 Espinoza L R, Bridgeford P, Lowenstein M. Polymyalgia rheumatica and giant cell arteritis: circulating immune complexes. J Rheumatol 1982; 9: 556-60.

16 Dales S, Fujinami R, Oldstone M B A. Infection with vaccinia favors the selection of hybridomas synthesising autoantibodies against intermediate filaments, one of them cross reacting with the virus haemagglutinin. $J$ Immunol 1983; 131: 1546-53.

17 Fujinami R S, Oldstone M B A, Wroblewska Z, Frankel M E, Koprowski H. Molecular mimicry in viral infection: cross reaction of measles virus phosphoprotein or of herpes simplex virus protein with human intermediate filaments. Proc Natl Acad Sci USA 1983; 80: 2346-50.

18 Mathews M B, Bernstein R M. Myositis autoantibody inhibits histidyl-tRNA synthetase: a model for autoimmunity. Nature 1983; 304: 177-9.

19 Naparstek Y, Andre-Schwarz J, Manser T, et al. A single germline $V h$ gene segment of normal $A / J$ mice encodes autoantibodies characteristic of systemic lupus erythematosus. $J$ Exp Med 1986; 164: 614-26.

20 Portnoi D, Freitas A, Holmberg D, et al. Immunocompetent autoreactive B lymphocytes are activated cycling cells in normal mice. $J$ Exp Med 1986; 164: 25-35.

21 Benlahrache C, Segond P, Anguier L, Bowet J P. Decrease of OKT8 positive $T$ cell subset in polymyalgia rheumatica. Arthritis Rheum 1983; 26: 1472-80.

22 Elling H, Elling P. Decreased level of suppressor/cytotoxic T cell (OKT8) in polymyalgia rheumatica and giant cell arteritis: relation to disease activity. $J$ Rheumatol 1985 ; 12 : 306-9. 